\title{
Editorial
}

\section{Polymers and Polymeric Composites with Electronic Applications}

\author{
Renbo Wei $\mathbb{D}^{1},{ }^{1}$ Xiufu Hua $\mathbb{D}^{2},{ }^{2}$ and Zhiyuan Xiong ${ }^{3}$ \\ ${ }^{1}$ Research Branch of Advanced Functional Materials, School of Materials and Energy, University of Electronic Science and Technology \\ of China, Chengdu 610054, China \\ ${ }^{2}$ Department of Scientific Research and Development, Tsinghua University, Beijing 100084, China \\ ${ }^{3}$ Department of Materials Engineering, Monash University, Victoria 3800, Australia \\ Correspondence should be addressed to Renbo Wei; weirb10@uestc.edu.cn
}

Received 27 August 2018; Accepted 27 August 2018; Published 11 November 2018

Copyright (c) 2018 Renbo Wei et al. This is an open access article distributed under the Creative Commons Attribution License, which permits unrestricted use, distribution, and reproduction in any medium, provided the original work is properly cited.

The development of the modern society has resulted in all kinds of electronic equipment and devices that are composed of elements which are made from electronic materials. These electronic materials contain the ceramics such as silicon used for the fabrication of the chips, metals like copper which appears in the printed circuits, and the polymeric materials utilized as the insulation, packing, and isolation, among others. In comparing with the inorganic electronic materials, the polymer-based electronic materials have attracted considerable attention due to their relatively low density, flexibility, easy processing, low manufacturing cost, and even recyclable. As a result, polymers and polymeric composites have shown increasing applications as the components in the electronic equipment and devices. What is more, some newly developed polymeric electronic materials are taking the place of their inorganic counterparts. Basing on their electronic applications, this special issue focuses on the preparation, characterization, performances, and applications of some polymer-based electronic materials.

Six original research papers and a review paper were collected in this special issue. These papers are themed on the fabrication and properties of polymeric electronic materials that can be potentially used as component in capacitors, solar cells, light emitting diode, and so on. The details of the topics in this special issue include the following: (1) effect of polar groups on the dielectric properties of dielectric polymers; (2) review of designing and preparing of high dielectric constant polymeric composites; (3) electric conductivity of polymeric composites with copper as a filler; (4) AC conductivity of polymeric composites with a conductive polymer as an additive; (5) designing of copolymers with optimized photoelectric properties through theoretical calculations; (6) microwave absorption properties of polyaniline and magnetite core-shell structured hybrid; and (7) polyimides as binder polymers on organic light-emitting diode panels.

We expect that the related researchers will get inspired by this special issue.

\section{Conflicts of Interest}

The guest editorial team declares no conflict of interest regarding the publication of this special issue.

\section{Acknowledgments}

We sincerely appreciate the contributions from the authors, the comments and suggestions from the reviewers, and the efforts and supports from the editorial staff members to this special issue.

Renbo Wei

Xiufu Hua

Zhiyuan Xiong 


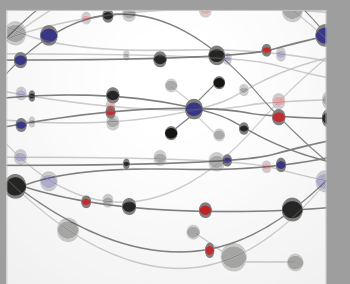

The Scientific World Journal
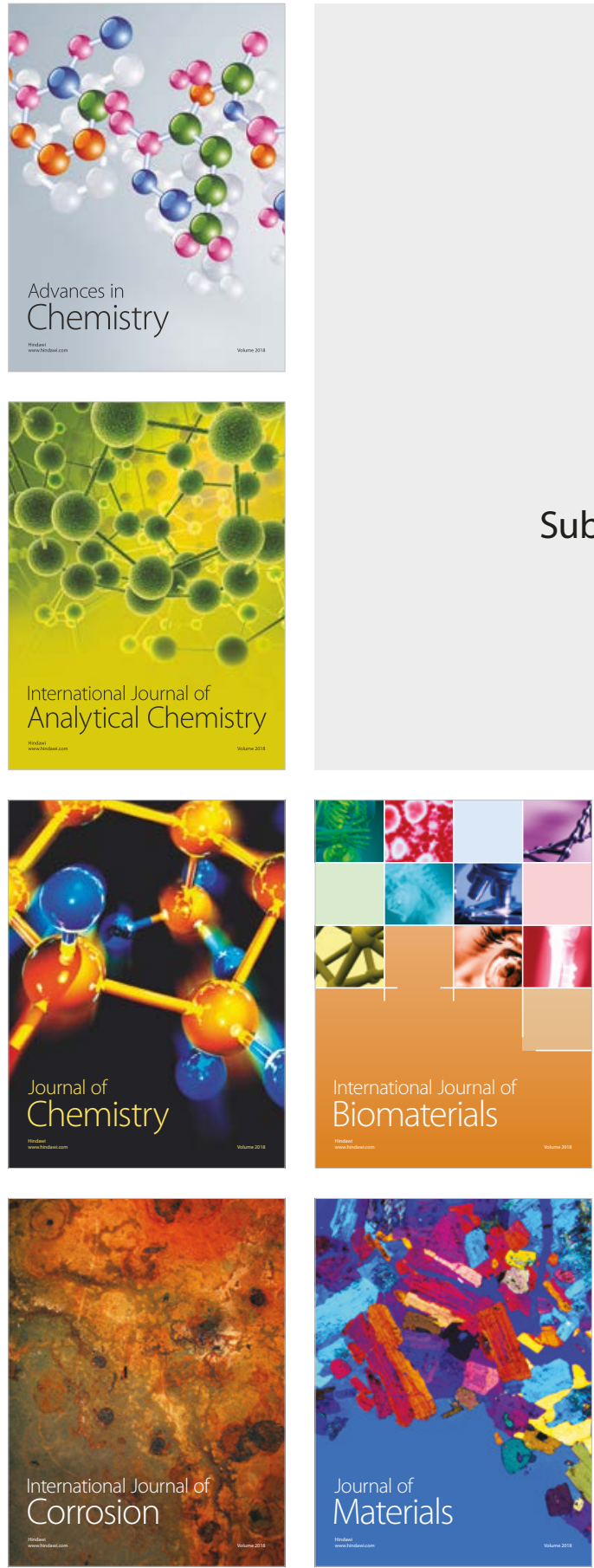

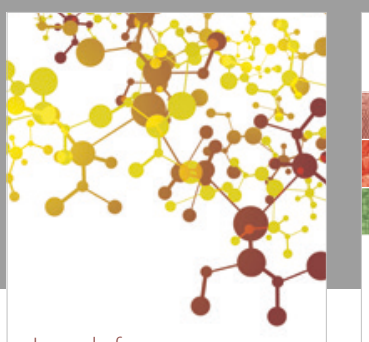

Journal of

Applied Chemistry
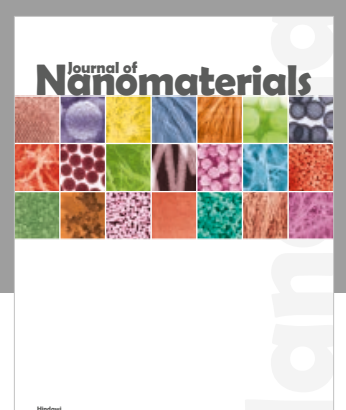

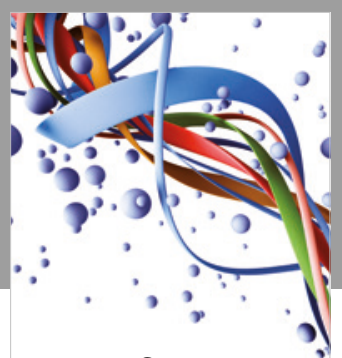

Scientifica

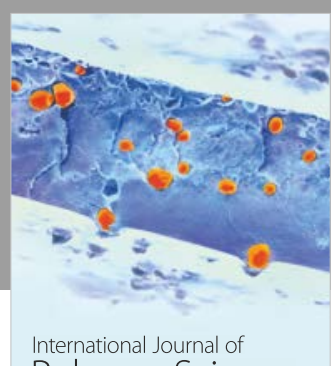

Polymer Science

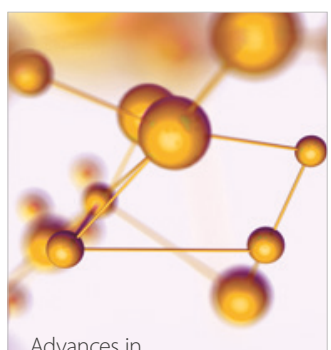

Physical Chemistry
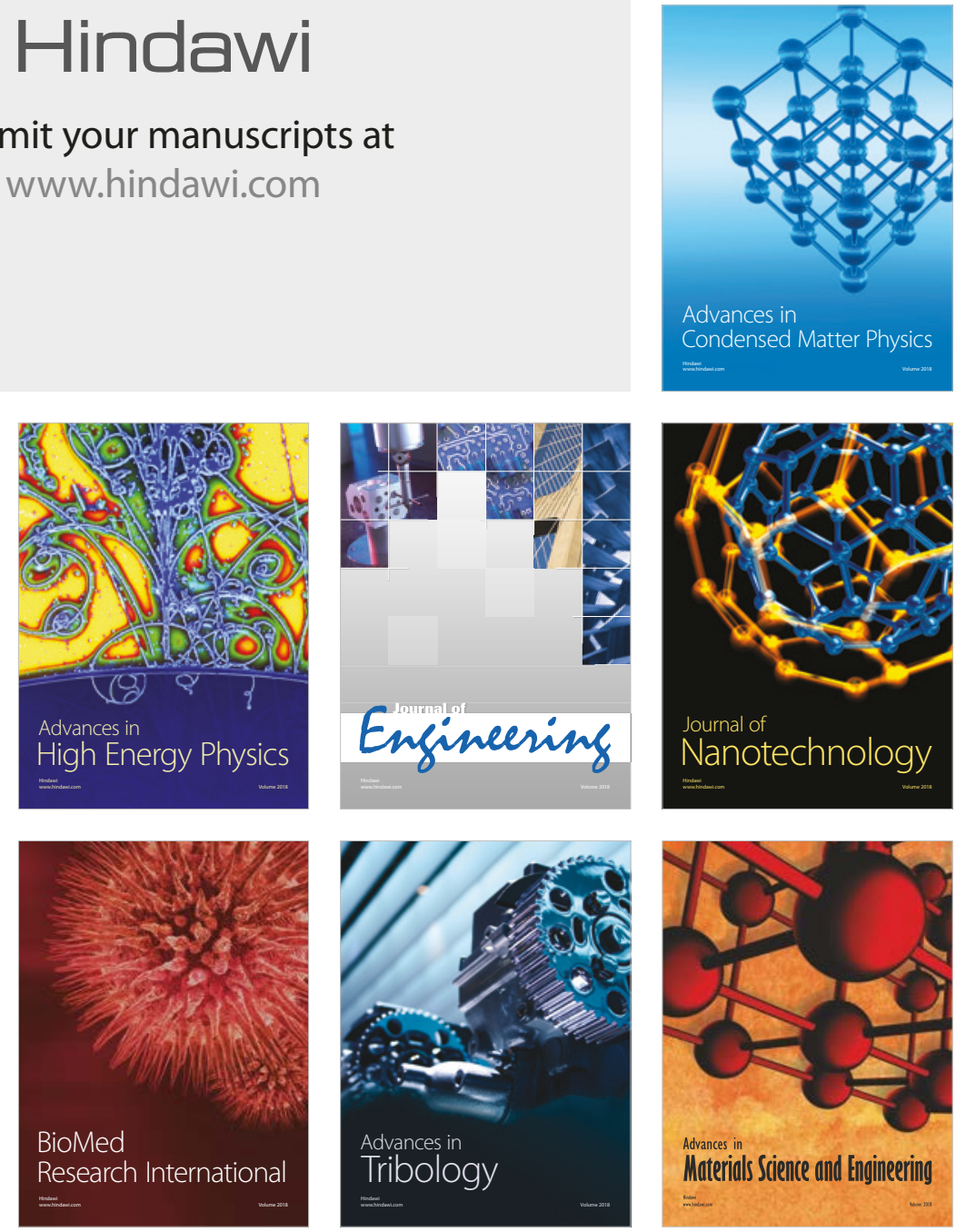